\section{Conjugated and polysaccharide anti-pneumococcal vaccines}

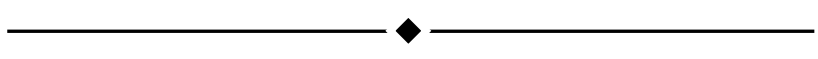

Dear Editor,

With respect of the article published by Di Nuzzo \& Fonseca ${ }^{1}$ we would like to point out that the information provided on the subject of immunization against pneumococcal diseases require correction, as described below.

In this article, four conjugated pneumococcal vaccines are presented. In Brazil, however, there is just one conjugated pneumococcal vaccine, the 7-valent vaccine conjugated with the CRM197 diphtheria toxin (serotypes 4, $6 \mathrm{~B}, 9 \mathrm{~V}, 14,18 \mathrm{C}, 19 \mathrm{~F}$ and $23 \mathrm{~F}$ ), which is indicated for administration from 2 months of age onwards (and not just from 2 months to 2 years) and can be given up to 5 years of age. Children who are first vaccinated with the 7-valent vaccine can later be given a dose of the 23 -valent vaccine in special cases (high risk). 2,3

Immunodepressed children over 2 years of age should be given two doses of the 7-valent vaccine (with a 2-month interval) and a single dose of the 23 -valent vaccine (2 months after the last dose of the 7-valent vaccine).

Recent studies of the efficacy and immunogenicity of the vaccine for premature patients, and also for older children requiring protection from non-invasive diseases (e.g. acute otitis media) are the references that have been used to widen the indications and the target-population of the vaccine. ${ }^{4-7}$

With respect of the 23-valent vaccine, this should be classified among the polysaccharide vaccines, composed of purified antigens from the polysaccharide capsules of 23 serotypes, being only available in our country for administration from 2 years of age onwards.

The 9 and 11-valent conjugated vaccines are not yet available commercially being in the final phases of research.

\section{Roberto Valdez}

Technical director, Previne Centro de Vacinação,

Porto Alegre, RS, Brazil

\section{Everton Sukster}

Technical director, Imune Clínica de Vacinação, Porto Alegre, RS, Brazil

\section{References}

1. Di Nuzzo DV, Fonseca SF. Anemia falciforme e infecções. J Pediatr (Rio J). 2004;80:347-54.

2. Centers for Disease Control and Prevention. Prevention of pneumococcal disease among infants and young children: recommendations of the Advisory Committee on Immunization Practices. MMWR. 2000;49(No. RR-9).

3. Centers for Disease Control and Prevention. Recommended childhood and adolescent immunization schedule-United States, July-December 2004. MMWR. 2004;53:Q1-3.

4. Black S, Shinefield H, Fireman B, Lewis E, Ray P, Hansen JR, et al. Efficacy, safety and immunogenocity of heptavalent pneumococcal vaccine in children. Pediatr Infec Dis $\mathrm{J}$. 2000;19:187-95.

5. Eskola J, Kilpi T, Palmu A, Jokinen J, Haapakoski J, Herva E, et al. Efficacy of a pneumococcal conjugate vaccine against acute otite media. N Engl J Med. 2001;344:403-9.

6. Shinefield H, Black S, Ray P, Fireman B, Schwalbe J, Lewis E. Efficacy, immunogenicity and safety of heptavalent pneumococcal conjugate vaccine in low birth weight and preterm infants. Pediatr Infect Dis J. 2002;21:182-6.

7. Whitney CG, Farley MM, Hadler J, Harrison LH, Bennett NM, Lynfield $R$, et al. Decline in invasive pneumococcal disease after the introduction of protein-polysaccharide conjugate vaccine. $\mathrm{N}$ Eng J Med. 2003;348:1737-46.

\section{Lung deposition, efficacy and effectiveness of spacer devices}

Dear Editor,

We read with great interest the article written by Rocha Filho et al. ${ }^{1}$ and now we would like to make some comments and questions about it:

1) In large-volume spacer devices, aerosol particles remain in suspension before being inhaled; thus, for better drug delivery, it is recommendable that the inhalation time should be exactly the same as that one used for smaller devices (often 30 instead of 10 seconds, as mentioned in the article).

2) As three-year-old preschoolers have a different respiratory dynamics from seven-year-old schoolchildren, it seems more appropriate to assess deposition according to age group instead of including these patients in the same analysis; what would the mean age of these groups have been? 